\title{
An Approach to the Oil Recovery Enhancement Method Considering Environment Pollution with Fuzzy Parameters
}

\author{
Adalat Karimov, Ulviyya Rzayeva \\ Department of Information Economy and technologies, Azerbaijan State University of Economics, Baku, AZ1001, \\ Azerbaijan
}

\begin{abstract}
Interest in oil recovery enhancement methods constantly increases. Scientists all over the world are engaged in research of the most effective methods for the development of oil fields. However, decline in the productivity oil wells still causes a range of problems, not only during their operation. Moreover, significant complications arise in managing the development of oil deposits, which eventually result in a reduction of technical and economic indicators of the process. In this paper, the issue of increase in oil recovery is viewed not only from the perspective of cost-effectiveness and time duration, but by means of intellectual systems we also consider the environmental pollution criteria.
\end{abstract}

Keywords-oil deposits; process efficiency; pollution; fuzzy indicators.

\section{INTRODUCTION}

Interest in oil recovery enhancement methods is increasing year by year. Research aimed at finding a science-based approach to the selection of the most effective field development technologies is constantly developing worldwide.

Despite the fact that consumption of petroleum products grows by each year throughout the world, efficiency of oil extraction from reservoirs with modern, industrial exploration methods of development in all oil-producing countries is considered unsatisfactory. Decrease in productivity of wells causes not only range of problems during their exploitation, but also significant difficulties in the deposits development managing. Eventually, this factors result in a reduction of technical and economic indicators of the process. Moreover, decline in the productivity of oil wells is often one of the main reasons for their complete cease and decommissioning. Existing technologies offer sufficiently broad information about the processes arising in the bottom hole formation zone in the process of development of reserves. We also obtain information about the techniques and technologies of controlling wells capacity, which helps us to achieve maximum technological and economic efficiency of the oil and gas fields' development.

\section{DISCUSSED PROBLEMS}

Review of modern techniques allows us to classify this parameter on three points:
- Increase in a petro-return of a layer, which implies the ratio of produced oil to its geological reserves

- Increasing debit - a volume of products produced from the well per unit of time

- Drilling of a new well

The basis for the solution of this problem should be a comprehensive engineering. It should include scientifically based methodology for selection the wells and centers of technology impacts with clarification of the criteria for effective usage of method. The results of laboratory studies of the application of technology to specific geological conditions and results of object modeling of the exposure spots and development process indicators should also be taken into account.. Moreover, the experience of the technology application in the fields-analogs and calculation method's economic profitability are required to be considered. There are many investigations towards costeffectiveness and time duration of the following activities $[1,2]$. During the operation of offshore fields environmental pollution is observed, especially in the sea. One of the causes of pollution is accidents on pipelines and field equipment system for collecting oil. During the accidents oil, mineralized water and other pollutants spill which harms the environment and the consequences can be detected only after a certain period of time passes. Surface and underground fresh water and soil pollution are the most dangerous consequences by oil and saline water spill. In the following study, in addition to cost-effectiveness and time duration we are considering other criteria - a measure of level of environmental pollution relatively to viewed technology. This problem belongs to the class of weaklyinformed, so all three indicators - output, time and pollution - are fuzzy [3].

\section{THE METHOD OF SOLUTION}

Suppose a set of oil wells $W=\left\{W_{1}, W_{2}, \ldots, W_{m}\right\}$ is given. The productivity falls because of influence of one or more reasons $R_{1}, R_{2}, \ldots, R_{n}$ in each of these wells. We introduce the criteria of environmental pollution $P_{1}, P_{2}, \ldots, P_{n}$. Well productivity is increased with the use of technologies $I_{1}, I_{2}, \ldots, I_{n}$ which are aimed to enhance oil within the time $T_{1}, T_{2}, \ldots, T_{n}$, taking into account the criteria of pollution. 
TABLE I CHARACTERISTICS OF SET OF OIL WELLS

\begin{tabular}{|c|c|c|c|c|}
\hline $\mathrm{Y}$ & $\left(I_{1}, T_{1}, P_{1}\right)$ & $\left(I_{2}, T_{2}, P_{2}\right)$ & $\ldots$ & $\left(I_{n}, T_{n}, P_{n}\right)$ \\
\hline$W_{1}$ & $\left(i_{11}, t_{11}, p_{11}\right)$ & $\left(i_{12}, t_{12}, p_{11}\right)$ & $\ldots$ & $\left(i_{1 n}, t_{1 n}, p_{1 n}\right)$ \\
\hline$W_{2}$ & $\left(i_{21}, t_{21}, p_{21}\right)$ & $\left(i_{22}, t_{22}, p_{21}\right)$ & $\ldots$ & $\left(i_{2 n}, t_{2 n}, p_{2 n}\right)$ \\
\hline$\ldots \ldots$ & $\ldots \ldots \ldots$ & $\ldots \ldots \ldots$ & $\ldots$. & $\ldots \ldots \ldots$ \\
\hline$W_{m}$ & $\left(i_{m 1}, t_{m 1}, p_{m 1}\right)$ & $\left(i_{m 2}, t_{m 2}, p_{m 2}\right)$ & $\ldots$ & $\left(i_{m n}, t_{m n}, p_{m n}\right)$ \\
\hline
\end{tabular}

For the variable "Debit" we define terms: very low, low, normal, not very high, high, for the variable "Time» - very little time, little time, a bit of time, a lot of time, for the variable "Contamination» - very dirty, dirty, moderately polluted, clean.

Estimates of given characteristics calculation is possible with the help of one of the methods of fuzzy classification, namely, a fuzzy operational characteristics method. To make a decision in such situation there are 4 criteria: "max / min", "max / max", "random max / min", "realism". Alternative results are obtained in a fuzzy type and the likelihood of their implementation is evaluated in the form of fuzzy membership functions. In this case, the method of decision analysis is implemented here. Suppose $X_{j 1}=\left(I_{j 1}, T_{j 1}, P_{j 1}\right)$ and $X_{j 2}=\left(I_{j 2}, T_{j 2}, P_{j 2}\right)$ are sets

of expected efficiency, $\mu_{A}\left(X_{j 1}\right), \mu_{B}\left(X_{j 2}\right)$ are membership's degrees to the set of expected effectiveness during selection.

In Azerbaijan increasing volume of oil extraction is more and more provided through the enhancing development of fields in the Caspian Sea. Thus, the proportion of heavy viscous oils production in total oil production increases. Commissioning of marginal fields and interest in the extraction of bitumen are increasing. On the other hand, there is a tendency to reduce the initial debits of wells, which changes the attitude to exploitation of old fields, since the total amount of production in old fields increases with respect to the new. Therefore, the value of mechanized methods of oil extraction is enhancing, which are the major methods in old fields. In this regard, a significant influence on the extraction process has a watering reservoir and production wells. In this regard, watering reservoir and wells' production have a significant influence on the extraction process. This is due to the fact that for maintenance predetermined oil rates necessary to pump large volumes of liquid (oil and water) from wells, which may be higher than the debits of the wells in the new fields [4].

The above features determine the difficulties of development of new deposits, increase of efficiency of operation already developed, assess the feasibility and efficacy of new technological processes and activities.

The main difficulty is the limited of the initial and obtained information in both qualitative and quantitative terms. The following table shows some of the reasons of oil reduction during operation of the oil well.
TABLE II. SOME OF THE REASONS OF OIL REDUCTION DURING OPERATION OF THE OIL WELL

\begin{tabular}{|c|l|c|}
\hline Code & $\begin{array}{l}\text { Parameters being the reason } \\
\text { of complications }\end{array}$ & $\begin{array}{l}\text { Conventional designation } \\
\text { of complications }\end{array}$ \\
\hline 1. & Lowering of the temperature & PT \\
\hline 2. & Factor of gas & QF \\
\hline 3. & $\begin{array}{l}\text { Speed of movement of oil } \\
\text { through the pipes }\end{array}$ & SST \\
\hline 4. & $\begin{array}{l}\text { Nonsmoothness of the pipe } \\
\text { walls }\end{array}$ & PFS \\
\hline 5. & $\begin{array}{l}\text { The efficiency of flowing } \\
\text { wells }\end{array}$ & PSS \\
\hline 6. & Drowned well & KSVJ \\
\hline 7. & $\begin{array}{l}\text { Number of narrow streams } \\
\text { when throwing of liquid }\end{array}$ & VOPSP \\
\hline 8. & $\begin{array}{l}\text { Term of the first layer of } \\
\text { paraffin }\end{array}$ & PO \\
\hline 9. & Subsidence of paraffin & SO \\
\hline 10. & Salinization & ZPP \\
\hline 11. & The appearance of sand plugs & PP \\
\hline 12. & Borehole plugs & KM \\
\hline 13. & Cartridge plugs & \\
\hline 14. & Calmatation & \\
\hline
\end{tabular}

On the lines of the following matrix are given oil wells, and on the columns - the signs of these wells (technical and technological parameters) [5]:

TABLE III. TECHNICAL AND TECHNOLOGICAL PARAMETERS

\begin{tabular}{|c|c|c|c|c|}
\hline $\begin{array}{l}\text { well } \\
\text { signs }\end{array}$ & $x_{1}$ & $x_{2}$ & ........... & $x_{m}$ \\
\hline$x_{1}^{+}$ & $x_{11}$ & $x_{12}$ & ........... & $x_{1 m}$ \\
\hline$x_{2}^{+}$ & $x_{21}$ & $x_{22}$ & $\ldots \ldots \ldots$ & $x_{2 m}$ \\
\hline ......... & ......... & ......... & .......... & .......... \\
\hline$x_{m}^{+}$ & $x_{n 1}$ & $x_{n 2}$ & $\ldots \ldots$. & $x_{n m}$ \\
\hline$H$ & $h_{1}$ & $h_{2}$ & .............. & $h_{m}$ \\
\hline
\end{tabular}

The table gives technical and technological parameters and the Hurst exponent for each well is given in the last row [6]. After the diagnosis of the condition of the oil well question there is the choice of a technology of enhanced oil recovery. To date, there is a number of defined areas of increasing or restoring the productivity of wells, among which are intellectual technology - the most rapid, efficient and effective means of influencing the bottom zone:

TABLE IV. INTELLECTUAL TECHNOLOGY OF ENHANCED OIL RECOVERY

\begin{tabular}{|l|l|l|}
\hline Code & Short name of the technology & Symbol of technology \\
\hline 1. & Do not require impact & NTV \\
\hline 2. & The surfactant acid element & KPAS \\
\hline 3. & Acid clay treatment & QKO \\
\hline 4. & Decalmatation & DKM \\
\hline 5. & $\begin{array}{l}\text { Composition based on of acid } \\
\text { sulphate } 3\end{array}$ & OSK3 \\
\hline 6. & Impact of acid imposition & KIV \\
\hline
\end{tabular}


Depending on the cause, which led to a decrease in oil recovery, recognition of the state of the well and the choice of algorithm, which determines the work of a technology based on the following assumptions: written information about the selected alternative in the form of fuzzy statements by the decision maker on the basis of the composite rules of inference is more appropriate.

In this paper, to solve this problem, a linguistic fuzzy production rules are used. Rules, assumptions and conclusions, which are formed on the basis of fuzzy sets, can be represented as

$$
\begin{aligned}
& R_{i}^{1} \text { : if } x_{1} \text { is } A_{i 1} \text { and...... and } x_{j} \text { is } A_{i j} \text { and......and } x_{m} \\
& \text { is } A_{i m}, \\
& R_{j}^{2} \text { : if } y_{1} \text { is } B_{j 1} \text { and..... and } y_{k} \text { is } B_{j k} \text { and..... and } \\
& y_{n} \text { is } B_{j n},
\end{aligned}
$$

then $z_{1}$ is $C_{q 1}$ and...... and $z_{q}$ is $C_{q k}$ and......and $z_{p}$ is $C_{q p}, i=\overline{1, m}, j=\overline{1, n}, \quad q=\overline{1, p}$.

Here $x_{i}$ are linguistic variables characterizing graduation of debit, $y_{j}$ - the cost of removing the causes of reducing of debit, $z_{q}-$ the cost of the degree of pollution.

\section{CONCLUSIONS}

The following rule is more suitable for decision-making, and, in general, linguistic fuzzy production rules, which are used as models for the creation of specific objects, and for building their evaluative models compared to others, are most frequently used. This approach was tested for both land and offshore deposits.

\section{REFERENCES}

[1] Shirinov K. F., Guliyev R.A., Kerimov A.K., Kerimova G.S., Balabekova M.O. The projecting of intelligent system of object selection and technology of enhanced oil recovery// Proceedings of Azerbaijan National Academy of Sciences. Series of physicotechnical sciences. 2003, No 2, pp. 64-67.

[2] Guliyev R.A. Economic analysis of methods for increasing oil in marginal wells/ Proceedings of the Conference dedicated to the 80th anniversary of G.A. Aliyev. Baku, 28 April, 2003, pp.104-105.

[3] Zadeh L.A. Concept of linguistic variable and its application to the adoption of approximate solutions. Mir, 1976.

[4] IPCC Special Report on Carbon dioxide Capture and Storage. Chapter 5, Underground geological storage.

[5] Rzayeva U.Sh., Aliyeva T.A., Azadova M.H. Forecasting of more informative attributes and their informative combinations of oil wells with neural networks/ First International Confe-rence On Soft Computing Technologies in Economy, Baku, Azerbaijan, 2007, pp. 60-61.

[6] Mirzadzhanzade A. Kh. On the motion of two-phase systems in a porous medium taking account of heat- and mass-transport processes // Journal of Engineering Physics and Thermophysics. Vol. 18 , pp. 702-706. 